\title{
Videojuegos y educación: análisis de tendencias en investigación
}

\section{Videogames and Education: Analysing of ResearchTrends}

\section{Videogames e educação: análise das tendências de pesquisa}

\author{
Diana Marín-Suelves* (iD orcid.org/0000-0002-5346-8665 \\ Graciela Esnaola-Horacek** (iD) orcid.org/0000-0002-1436-6041

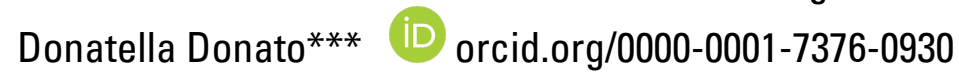

\begin{abstract}
Para citar este artículo
Marín-Suelves, D., Esnaola-Horacek, G. y Donato, D. Videojuegos y educación: análisis de tendencias en investigación. Revista Colombiana de Educación, 1(84), 1-17. https://doi.org/10.17227/rce.num84-12125
\end{abstract}

Fecha de recepción: 24/07/2020

Fecha de recepción: 27/12/2020

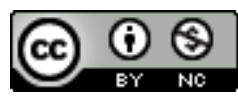

* Doctora en Psicología social y de las organizaciones, Universitat de València, Comunitat Valenciana, España. Correo: Diana.marin@uv.es

** Docente investigadora titular, Ciencias Sociales, Universidad Nacional de Tres de Febrero, Buenos Aires, Argentina. Correo: graesnaola@gmail.com

*** Universtat de València, Comunidad Valenciana, España: Correo: Donatella.Donato@uv.es 


\author{
Palabras clave: juego \\ educativo; investigación; \\ enseñanza; tecnología; \\ desarrollo de la educación
}

\section{Resumen}

Mucho se ha escrito en los últimos tiempos acerca de las posibilidades y controversias del uso de los videojuegos en educación. Para conocer las tendencias en investigación, a través de la productividad, impacto, colaboración y difusión, se realizó un análisis bibliométrico sobre 226 documentos disponibles en la base de datos Scopus. Además, se complementó con un análisis de contenido de los 62 artículos disponibles en acceso abierto. Los resultados muestran el interés por el estudio de esta cuestión y el auge en la última década, el peso de países como España, y el elevado impacto de casi la mitad de los artículos. Además, se confirma lo esperado según la Ley de Lotka y Bradford. Las investigaciones confirman que los videojuegos tienen efectos positivos en el aprendizaje, la motivación y la dinámica de la clase, sin olvidar el papel fundamental del profesorado, el diseño y la finalidad del propio juego. Por último, se señalan futuras líneas de investigación vinculadas a la necesaria formación del profesorado o la evaluación de los videojuegos desde una vertiente pedagógica.

\section{Abstract}

Much has been recently written about the possibilities and controversies of using video games in education. In order to know the research trends, through productivity, impact, collaboration and dissemination, a bibliometric analysis was performed on 226 documents available in the Scopus database. This was supplemented with a content analysis of 62 open-access articles. The results show the interest of studying this question and the boom of the past decade, the weight of countries like Spain, and the strong impact of almost half the articles. According to the Law of Lotka and Bradford, what was expected was confirmed. Research confirms that video games have positive effects on learning, motivation and class dynamics, without forgetting the fundamental role of teachers, and the design and purpose of games. Finally, future research lines related to necessary teacher training or the evaluation of video games from a pedagogical perspective are indicated.

\section{Resumo}

Muito tem sido escrito nos últimos tempos sobre as possibilidades e controvérsias do uso de videogames na educação. Para conhecer as tendências da pesquisa, por meio da produtividade, impacto, colaboração e disseminação, foi realizada uma análise bibliométrica em 226 documentos disponíveis no banco de dados Scopus. Além disso, foi complementada por uma análise de conteúdo dos 62 artigos disponíveis em acesso aberto. Os resultados mostram o interesse no estudo dessa questão e o boom da última década, o peso de países como a Espanha e 0 alto impacto de quase metade dos artigos. Além disso, o que é esperado é confirmado de acordo com a Lei de Lotka e Bradford. Pesquisas confirmam que os videogames têm efeitos positivos na dinâmica de aprendizado, motivação e classe, sem esquecer o papel fundamental dos professores, o design e o objetivo do jogo. Por fim, são apontadas futuras linhas de pesquisa relacionadas à necessária formação de professores ou à avaliação de videogames sob uma perspectiva pedagógica. 


\section{Introducción}

Hoy podemos afirmar que los videojuegos constituyen una expresión de la cultura digital interactiva. Transitando la segunda década del siglo XXI podemos definir a la cultura lúdica como un componente de gran parte de las rutinas y desempeños de los sujetos. Ahora bien, ¿cómo podemos definir este cambio de época definida como cultura lúdica? Advertimos que estamos transitando desde la cultura Gutenberg que impuso un uso generalizado de la escritura hacia la cultura lúdica-digital.

Nos sostenemos en esta advertencia: los usos y prácticas van generando huellas psicosociales en nuestras acciones: el uso generalizado selló prácticas en la modernidad. Así como necesitamos poner orden a la oralidad y establecer coordenadas espacio-temporales que posibiliten la escritura, estas prácticas sobre el papel también se van imprimiendo en la organización social: una sociedad jerarquizada y ordenada que fue acompañando estas huellas. Este concepto estructural produce un residuo cognitivo (San Martín, 1995, p. 158) que es muy interesante porque se refiere a una mente que dialoga con la cultura. En la modernidad teníamos como objetivo una sociedad jerarquizada, ordenada, segmentada. La escritura pasó por el mismo tránsito cultural. Desde la oralidad hasta la escritura. Cuando se ordena ese mundo del rumor y se fija una orientación, se jerarquiza incluso el valor de la escritura. Siguiendo este pensamiento vemos que, promediando la primera década del siglo XXI, hallamos un verdadero cambio de época más allá de una época de cambios. El nuevo paradigma cultural denominado digimodernismo (Kirby, 2009) implica diversos medios y nuevas ideas sobre la creación de textos y su funcionamiento, produce formas distintivas de categorizar y explicar el nuevo mundo digital y nuestro lugar en él. Ahí inscribimos la cultura lúdica. Prácticas cotidianas, signadas por la expansión de los videojuegos en entornos casuales, móviles y que pueden ser ejecutados en tiempos estrechos y ágiles. La institución escolar también participa de esta cultura rechazando prácticas docilizantes y memorísticas, propias de otros tiempos didácticos. Los estudiantes demandan materiales didácticos que no solo sean soportes de contenidos, sino que, además sean ágiles y divertidos. Se ha abierto un nuevo nicho para el desarrollo de videojuegos fáciles de acompañar los temas curriculares más arduos.

El proceso de digitalización produce un cambio en dos componentes constitutivos de la identidad social: el espacio y el tiempo. La escritura demanda un espacio estático de exhibición, de serenidad y de contemplación de ese objeto que es la palabra, el conocimiento, el libro. La contemplación es muchas veces lo que pide el maestro, el silencio. Aquí surge un obstáculo para incluir videojuegos en las aulas que el profesor debe sortear, valorando la ganancia de jugar, de reír y de caer inmersos en una narrativa que facilita el progreso en la resolución de problemas. El profesorado que incluye videojuegos en las aulas valora el desarrollo de competencias y habilidades que se producen en los equipos de juego que se divierten al aprender. La alegría es otro componente que instalan los juegos en el aula. En tiempos posmodernos los relatos lineales, el orden secuencial, está en crisis porque estos nuevos textos demandan o se construyen en base a la interactividad. Un texto si no es interactivo, no es dinámico y si no permite hacer otros trazados cansa, agota, pierde el interés. 
El usuario es un prosumidor que busca intervenir: es interactividad cultural. El espacio, hoy, es inmersivo, y entró en el espacio de la lectura y en la construcción de sentido. Un espacio participativo, de múltiples ventanas. Las neurociencias han hallado en la educación un nuevo objeto de estudio: nuestras neuronas que eran secuenciales ahora tienen múltiples posibilidades de conectarse y aparecen otro tipo de conexiones. La sociedad tenía un tiempo lineal con rutinas que nos estructuraban la vida, un tiempo de la intimidad, un tiempo laboral y un tiempo para resolver cuestiones de cotidianidad. Tiempos separados, vinculados a los ámbitos cotidianos. Hoy se ha producido un remix temporal que ha mezclado el tiempo laboral con el tiempo cotidiano, desde que apareció esta posibilidad de estar conectados sincrónicamente, se mezclan los tiempos y los espacios, se puede estar comunicado con gente que habita espacios lejanos y se desconoce al vecino. La estructura del pueblo se ha convertido, como bien expresa Castells (1997), "en una serie de chalecitos individuales" ( $p$. 374). Aparece una nueva categoría de sujeto vinculado a las nuevas prácticas culturales.

Si entendemos que los sujetos escolares son sujetos inmersos en la cultura y no son sujetos biológicos aislados, vamos a poder reinventar la didáctica de estos estudiantes que hoy cuestionan a una enseñanza que aún no contempla estas características de la cultura lúdica que atrapa a los estudiantes. Este sujeto del siglo XXI ya no es un sujeto que está en un lugar, en un tiempo y en un espacio. Es un sujeto que se mueve, es un sujeto que volvió a ser nómade, traslada su oficina en su móvil y está teletrabajando o cursando una carrera en su hogar. Cobo y Moravec (2011) lo definen como sujetos knowmads (know: "conocimiento"; mads: "nómade"), el conocimiento nómade. Esta metáfora describe un conocimiento situado: la institución escolar, la biblioteca, la universidad, el libro de texto, hacia un sujeto/objeto nómade que se va construyendo y reconstruyendo permanentemente. Moravec escribe con Romaní Cristóbal Cobo el texto Aprendizaje invisible (2011), y definen el sujeto como un sujeto nómade y una knowmad society, una sociedad nómade donde las fronteras son cada vez más indefinidas. Los aportes de Bauman (2003), con su descripción de modernidad líquida, nos permiten describir a la institución/escuela como lo sólido en esta modernidad líquida. Convivir con esa incertidumbre es un proceso complejo y más aún situándolo en educación, ya que nuestra tarea es siempre en perspectiva. Estos conceptos son muy interesantes para comprender los cambios que requiere el nuevo paradigma de enseñanza ya que sitúa las buenas prácticas en categorías culturales.

En estas conceptualizaciones socioculturales hallamos las bases para definir qué concepto de videojuego educativo adherimos. Consideramos un videojuego educativo como un material didáctico digital (MDD), ya que tiene como finalidad reforzar contenidos diseñados explícitamente para atender a los contenidos a enseñar. Considerando otra didáctica, la tradicional, se presentarían en primer lugar, los contenidos curriculares explicados por el profesor y secuenciados según el programa. Una vez explicado el tema se procede a realizar una actividad o bien un juego para reforzar contenidos. Aquí la concepción de videojuego educativo está atada al contenido escolar. El MDD cumple una función motivacional o de refuerzo de conducta, una visión pedagógica que fue desarrollada durante el siglo pasado con más o menos éxito, pero otro era el contexto sociocultural. Hoy el paradigma de aprendizaje ha cambiado. No es necesario un trabajo explícito ya que se aprende haciendo, en cada oportunidad. Aquí es que podemos definir al MDD (y en particular pensemos en los videojuegos) como herramientas didácticas facilitadoras de aprendizaje. Los componentes de desarrollo de videojuegos ofrecen múltiples posibilidades de aprendizaje que no cumplen estrictamente con 
los contenidos de un programa y lo exceden, enriqueciéndolo: una narrativa como marco simbólico, las mecánicas lúdicas y la estética que invitan al autoaprendizaje y al desarrollo del pensamiento estratégico para la resolución de problemas, por ejemplo.

Nuestra definición de videojuego educativo hace referencia a una herramienta digital interactiva que busca desarrollar competencias cognitivas y psicosociales, básicamente enmarcados en un entorno digital lúdico. Por definición, los desarrolladores deberán construir videojuegos que enseñen competencias pero que no dejen de ser juegos, esto es, conserven la riqueza del aprendizaje basado en juegos. En los artículos evaluados en su contenido observamos cómo se diseñan los videojuegos, cómo se desarrollan, cómo aprende a jugar el que no sabe, cómo van cambiando para poder entender esa nueva mente, esa nueva posibilidad, desde los dos lados, desde el lugar de gamer, del consumidor y el game design. Aspectos de la industria cultural de desarrollo de videojuegos que se desconocen en el universo educativo. Los estudiantes consumen extensas horas jugando videojuegos y la cultura lúdica se está expandiendo a las narrativas transmedia. Aunque algunos estudios demuestran que el tiempo de juego es un aspecto necesario, pero no suficiente para la adicción a los videojuegos, en la que intervienen las diversas recompensas extrínsecas e intrínsecas que llevan a jugar durante cantidades excesivas de tiempo (Chamarro et al., 2020).

Ahora bien, siguiendo los últimos artículos científicos evaluados pensamos en la posibilidad de inscribir una pedagogía transmedia que pueda dialogar entre estos dos mundos. El nuevo paradigma didáctico propone dialogar con ese mundo lleno de imágenes para después trasladar esa imagen a la experiencia y transformarla en conocimiento en un salto cognitivo. Se debería pasar de una pedagogía de enunciación a una pedagogía de la experimentación, de la participación, de buscar estas posibilidades que nos están dando los medios para poder entender el mundo de nuestros estudiantes. Quedan explicitadas las bases teóricas para comprender por qué es necesario incorporar videojuegos a las prácticas de enseñanza ofreciendo una continuidad en el aprendizaje de usuario al que están acostumbrados los estudiantes, una estrategia lúdica que los lleva a buscar información y resolver problemas prácticos. El desafío del profesorado es, de acuerdo con los análisis de contenido coincidentes, evaluar distintas posibilidades en los videojuegos que acompañen el aprendizaje basado en juegos digitales y sus buenas prácticas de enseñanza.

Este artículo tiene como finalidad relevar antecedentes académicos que, con distintos enfoques, focalizan en la inclusión de videojuegos en las aulas. Con este estudio se pretendió dar respuesta a qué se está investigando sobre videojuegos en educación, desde una perspectiva cienciométrica y de contenido. Los objetivos específicos fueron conocer el grado de producción, la colaboración, la dispersión e impacto en este campo y las características principales de los estudios realizados lo que puede contribuir al diseño de programas o aplicaciones educativas de los videojuegos con ciertas garantías de éxito, ya que, estarán basadas en la evidencia científica. 


\section{Métodología}

Este trabajo consiste en un estudio bibliométrico, de tipo descriptivo y carácter retrospectivo, con la metodología propia de estos abordajes (Moreno, 2019), lo que permite mostrar una visión general del estado del arte. El objetivo fue cuantificar los principales rasgos de la literatura científica centrada en un área específica (Tomás-Górriz y Tomás-Casterá, 2018), como es el uso de videojuegos en educación y analizar las tendencias en la investigación, tal y como indican Zulueta y Bordons (1999).

Se seleccionó la base de datos Scopus, por su reconocido prestigio, dada su cobertura temporal y número de publicaciones, tal y como afirman García et al. (2020), o MartínezHeredia y Moreno (2020). La búsqueda y análisis se realizó durante mayo de 2020, para conocer la tendencia en este año, a través de los datos del primer cuatrimestre. Para aumentar la fiabilidad y la especificidad de esta propuesta se planteó un mesoanálisis, limitando los resultados a la producción científica en el área de las Ciencias Sociales (King, 1987), ya que, el objetivo era analizar las consecuencias o implicaciones del uso de los videojuegos en educación. Se han utilizado indicadores bibliométricos específicos para el análisis de los datos, propuestos por Aleixandre (2010), partiendo de variables estructurales como la productividad científica, la colaboración, la dispersión y el impacto. Los documentos seleccionados para el análisis bibliométrico son aquellos obtenidos tras la búsqueda en título, palabras clave y resumen los términos: videogame OR serious game AND education, ya que, la introducción de términos como play game o school no aumentaron el número de resultados. Se aplicaron criterios de inclusión y exclusión, como el filtro temporal limitando a la última década y la tipología de documentos: artículos. En la figura 1 se muestra el proceso para la selección de los documentos aquí analizados. Se diferencian tres fases: la identificación de textos susceptibles de análisis; el cribado, eliminando documentos no atingentes a los objetivos de este trabajo; y por último, la inclusión de documentos para el análisis bibliométrico. A partir del análisis de los documentos por dos investigadoras se seleccionaron 226 artículos, con una elevada fiabilidad intersujetos y un nivel de acuerdo alto (Altman, 1991) con un resultado en la prueba kappa de Cohen de 0,697. 


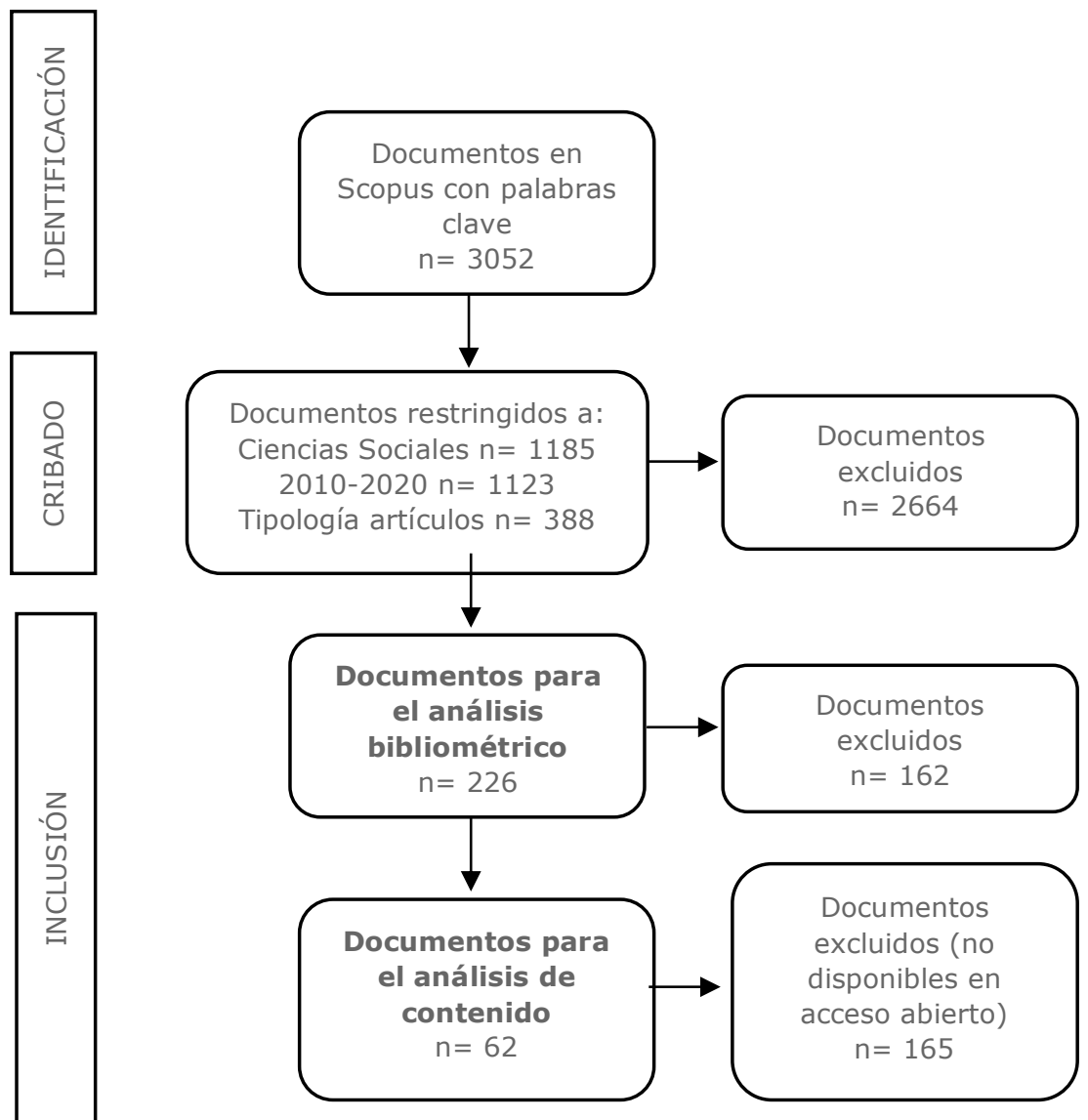

Figura 1. Diagrama de flujo del proceso de selección de documentos

Fuente: adaptación del método Prisma.

Además, se decidió complementar este estudio con un análisis de contenido, seleccionando los documentos disponibles en acceso abierto, que fueron un total de 62 artículos. Para este análisis se recurrió a una plantilla de registro en la que se consideraron la muestra, las etapas educativas, las áreas y los resultados obtenidos. Por último, para la representación gráfica de los resultados se utilizó el software vosviewer (Van Eck y Waltman, 2011).

\section{Resultados}

En este apartado se muestran los hallazgos del estudio bibliométrico realizado y del análisis de contenido. Respecto al estudio bibliométrico se tomaron en consideración diversos indicadores para el análisis de la producción, la colaboración, la dispersión y el impacto.

En primer lugar, en cuanto a la productividad científica, se tomó en consideración el número de documentos publicados, en el área de Ciencias Sociales. Tras la identificación, mediante la búsqueda en la base de datos Scopus, y el cribado, aplicando los criterios de inclusión y exclusión previamente comentados, se seleccionaron un total de 226 artículos. La producción diacrónica, representada en la figura 2 , indica que la cantidad de publicaciones ha ido 
aumentando a lo largo de los años, alcanzando el número máximo en 2019, con un total de 42 artículos.

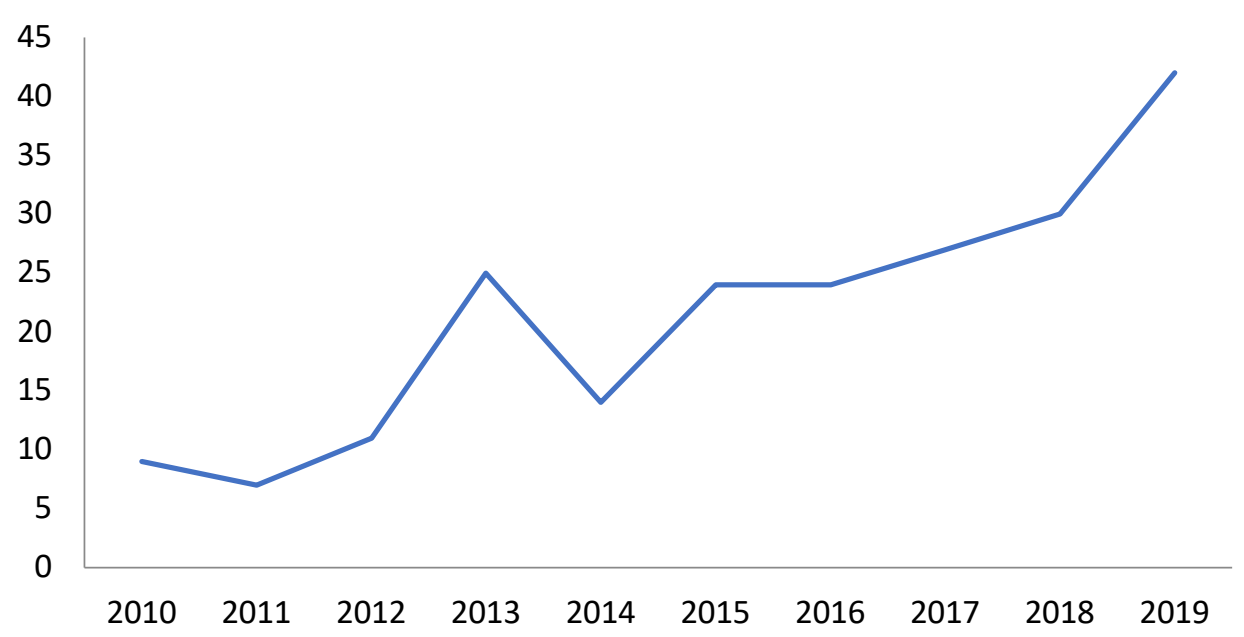

Figura 2. Publicaciones por año

Fuente: elaboración propia a partir de Scopus.

En cuanto a la productividad personal, un total de 160 autores firman los 226 artículos. Este dato se analiza en base a la ley de productividad científica de Lotka, que establece que solo un reducido número de autores publican una cantidad importante de textos centrados en una misma temática. Tal y como se observa en la tabla 1, en este caso predominan los productores ocasionales, ya que, un total de 117 autores (73\%) solo cuentan con una publicación y 37 autores (23\%) han elaborado 2 artículos. El resto (4\%) se pueden considerar productores medianos, y no se ha encontrado ningún gran productor.

\section{Tabla 1}

Número de artículos por autor

\begin{tabular}{cc}
$\begin{array}{c}\text { Número de } \\
\text { artículos }\end{array}$ & $\begin{array}{c}\text { Número } \\
\text { autores }\end{array}$ \\
\hline 1 & 117 \\
2 & 37
\end{tabular}




$\begin{array}{ll}3 & 0 \\ 4 & 5 \\ 5 & 1\end{array}$

0 5 1

Total $\quad 160$

Fuente: elaboración propia.

Como medianos productores destacan Fernando Luis Almeida (Universidade do Porto), Sylvester Arnab (Coventry University), Francesco Bellotti (Università degli Studi di Genova), Sara Isabella de Freitas (Murdoch University) y Alessandro de Gloria (Università degli Studi di Genova), que firman 4 artículos cada uno de ellos, y Riccardo Berta (Università degli Studi di Genova) con 5 artículos. Desde una perspectiva de género resulta necesario destacar la baja representación de las mujeres en este campo de estudio.

Por otra parte, se consideraron los idiomas en los que se han publicado los artículos científicos analizados (figura 3). La mayoría de ellos (85\%) están escritos en inglés, y un $12 \%$ en español. Además, aparecen documentos publicados en cuatro idiomas más, como son el portugués (Esqueda y Fernandes, 2019; Finco y Fraga, 2012; Finco et al., 2015; Saldanha et al., 2018), alemán (De Moll, 2019), francés (Ferreira, 2014) y holandés (Smallenbroek et al., 2015), lo que demuestra el interés existente en difundir los conocimientos generados sobre esta temática.

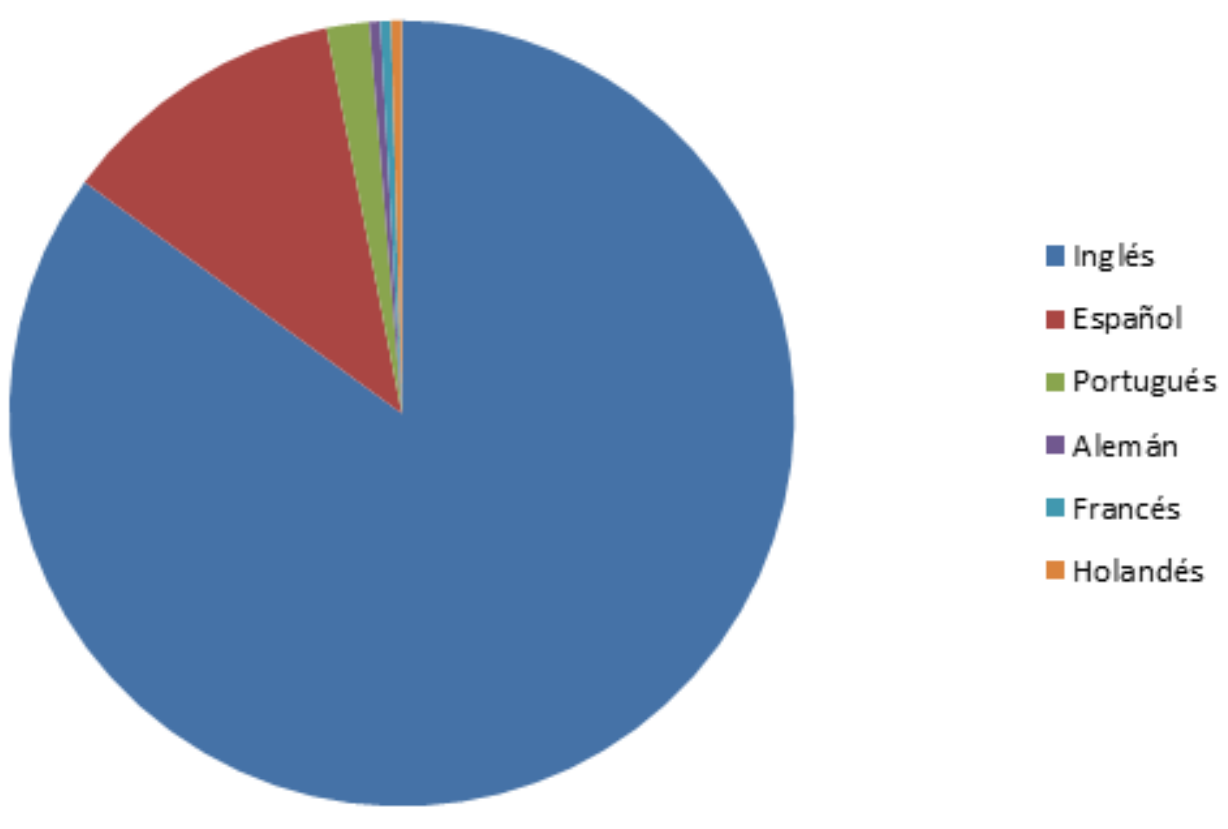


Figura 3. Idioma de los artículos.

Fuente: elaboración propia a partir de Scopus.

En segundo lugar, por lo que respecta a la información obtenida a través de los indicadores de colaboración, destaca la existencia de importantes redes entre investigadores. Como muestra la tabla 2, la mayoría de los trabajos fueron escritos en colaboración $(87,6$ \%).

\section{Tabla 2.}

Número de autores por artículo

\begin{tabular}{ccc}
$\begin{array}{c}\text { Número de } \\
\text { firmantes }\end{array}$ & N & $\%$ \\
\hline 1 & 28 & $\begin{array}{l}12, \\
4\end{array}$ \\
& & 29, \\
2 & 67 & 6 \\
& & 24 \\
3 & 55 & 3 \\
4 & 38 & 16, \\
5 & 14 & 8 \\
Entre 6 y 10 & 22 & 6,2 \\
Más de 10 & 2 & 9,7 \\
& & 1 \\
\hline Total & 226 & 100 \\
\hline
\end{tabular}

Fuente: elaboración propia.

Existen dos artículos con más de 10 firmantes. El trabajo de Lanzotti et al. (2020), escrito en colaboración por investigadores de Estados Unidos e Italia, aborda la capacitación en seguridad de trabajadores y concluyen la utilidad de los videojuegos para mejorar la atención y habilidades en contextos laborales. Mientras que el trabajo con una mayor cantidad de autores es el de Dunbar et al. (2017), un total de 17 investigadores procedentes de diferentes universidades de Estados Unidos. En este trabajo se analiza la efectividad de un videojuego para reducir con los estudiantes los sesgos cognitivos. 
En la figura 4, se muestra la red de colaboración internacional, en la que aparecen representados aquellos países que cuentan con colaboraciones en alguno de los artículos. Por poner un ejemplo, uno de los más recientes es el trabajo de Torres-Toukoumidis et al. (2020), en el que investigadores de Ecuador, España e Italia analizan la relación entre variables como el nivel de educación y la fuente de inspiración, el propósito del videojuego diseñado y las habilidades a desarrollar, que intervienen en el desarrollo de videojuegos en el marco del Global Game Jam. Se concluye que no existen diferencias entre los jóvenes creadores y los grandes expertos en cuanto a la pasión puesta en el proceso de desarrollo de los videojuegos. Señalan que la fuente de inspiración depende del género o de la mecánica del juego, y que el objetivo es el aprendizaje de una habilidad técnica, como el diseño y la programación, y el disfrute de los jugadores.

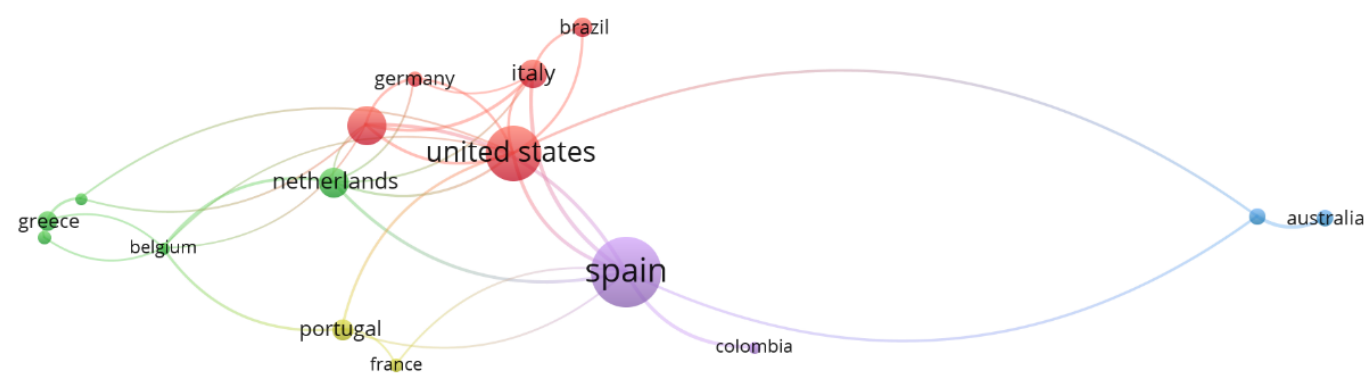

\section{\& vosviewer}

Figura 4. Red de coautoría.

Fuente: vosviewer.

En tercer lugar, se analiza la dispersión a través de la ley de Bradford, en la que se relaciona la cantidad de revistas y de artículos sobre un tema. En la figura 5, se ilustran tres zonas. El núcleo está formado por un reducido número de revistas $(n=18)$ que contienen la mitad de los artículos analizados $(n=112)$. En la zona 1 , se concentran una mayor cantidad de revistas $(n=37)$ en las que se han publicado un menor número de artículos $(n=56)$. Y en la zona 2 , se encuentran 58 revistas que han publicado solo un artículo sobre videojuegos en educación. 
Figura 5. Dispersión de la literatura.

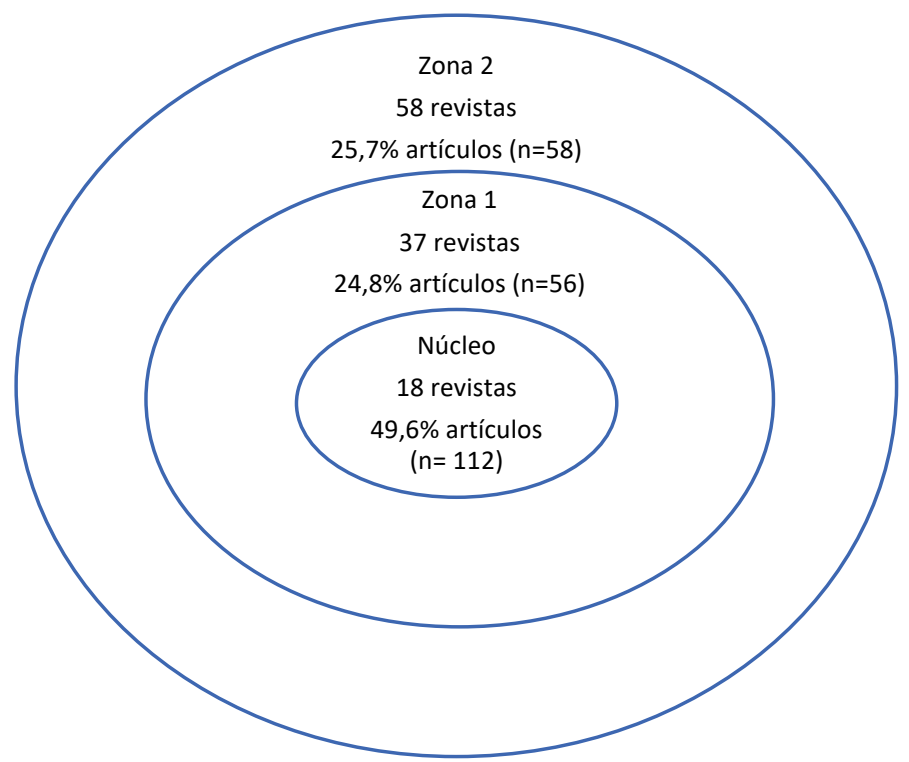

Fuente: elaboración propia.

Las revistas en las que se han publicado mayor cantidad de artículos sobre la implementación de videojuegos en educación son: Computers and Education (9\%), British Journal of Educational Technology (6\%), International Journal of Emerging Technologies in Learning (5 \%) e International Journal of Game Based Learning (5\%).

Por último, para el análisis bibliométrico se consideraron indicadores de impacto, como la procedencia geográfica, las instituciones, el número de citas y la red de citaciones entre autores.

En cuanto al peso de cada país (figura 6), destaca la supremacía de España, que cuenta con alrededor de un cuarto del total de artículos publicados sobre videojuegos en educación $(26,1 \%)$, seguida de EE. UU. (18,6 \%) y Reino Unido (10,2 \%). Existen diferencias importantes en el tamaño bibliométrico de cada país, pero se encuentran documentos escritos desde 48 países, tan distantes y diferentes como Cuba (López et al., 2018), India (Saravanan y Balasaravanan, 2018), Malta (Khaled y Vasalou, 2014), o Tailandia (Sipiyaruk et al., 2017), con un artículo, respectivamente. 


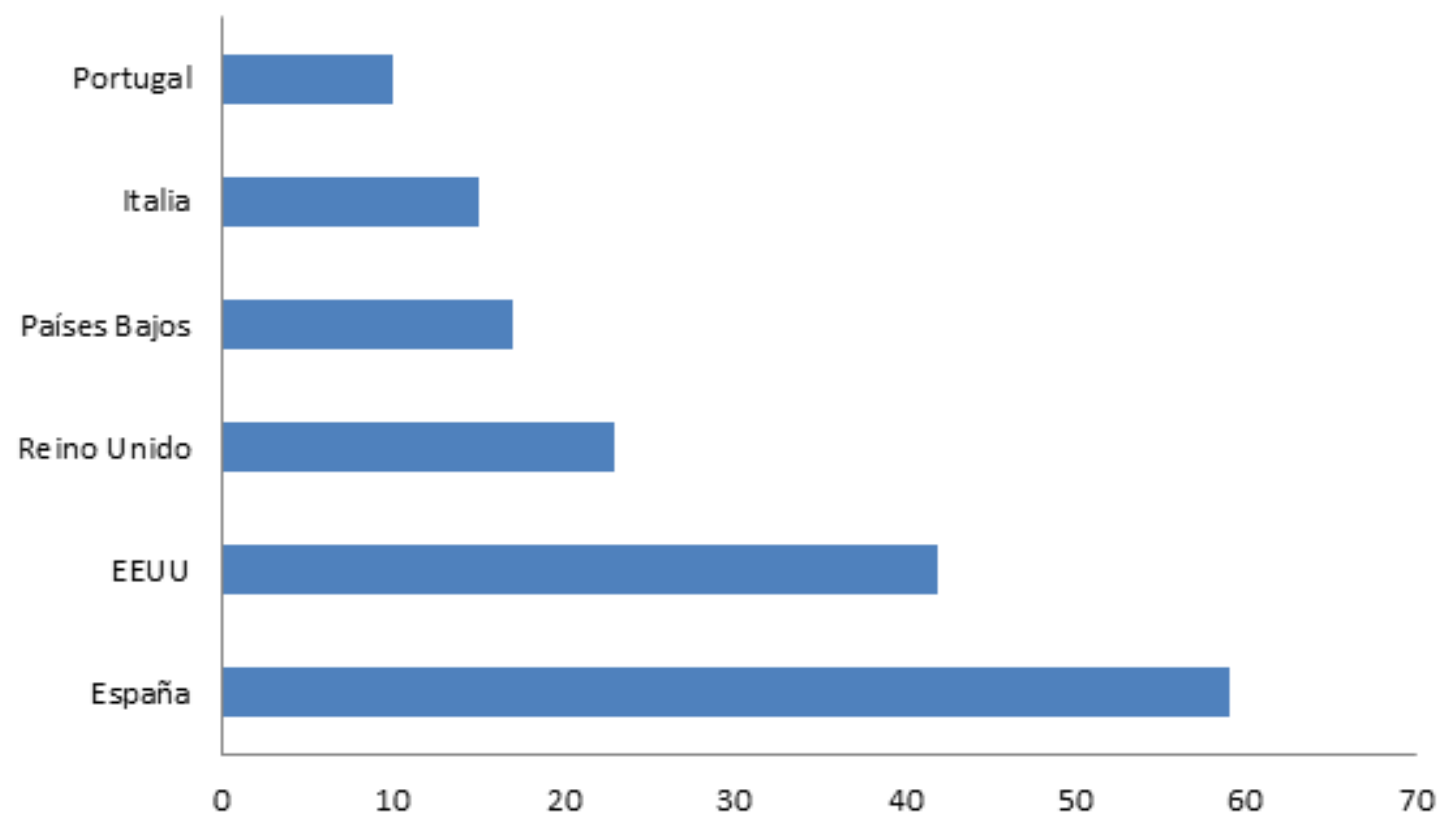

Figura 6. Publicación por país

Fuente: elaboración propia a partir de Scopus.

Respecto a las instituciones desde las que se está trabajando esta cuestión destacan universidades españolas como la Complutense de Madrid, la Autónoma de Madrid, la de Granada, la de València, la de Córdoba o la Rovira i Virgili. Además de otras extranjeras como Utrecht University, Coventry University, Università degli Studi di Genova o Universidade do Porto.

Por otra parte, si se considera la repercusión de los artículos en base al número de citas recibidas, en la tabla 3 se observa que la mayoría de ellos tienen un impacto nulo o escaso, ya que un $68,1 \%$ ha recibido entre cero y cinco citas.

\section{Tabla 3}

Número de citas por artículo

\begin{tabular}{ccc} 
Número de citas & $\mathrm{N}$ & $\%$ \\
\hline 0 & 57 & $\begin{array}{l}25, \\
2\end{array}$
\end{tabular}

$\begin{array}{cc}1-5 & 97 \quad 42 \\ & 9\end{array}$




\begin{tabular}{ccc} 
6-10 & 22 & 9,7 \\
$11-20$ & 18 & 8 \\
$21-30$ & 11 & 4,9 \\
$31-50$ & 8 & 3,5 \\
Más de 50 & 7 & 3,1 \\
Más de 100 & 6 & 2,7 \\
\hline Total & 226 & 100 \\
\hline
\end{tabular}

Fuente: elaboración propia.

En la tabla 4 se presentan los datos fundamentales de los artículos más citados, considerando que son dignos de mención aquellos que acumulan más de un centenar de citas.

\section{Tabla 4}

Artículos más citados

\begin{tabular}{ccc} 
Autor/año $\quad$ Título & Revista & $\begin{array}{l}\text { Núme } \\
\text { ro de } \\
\text { citas }\end{array}$ \\
\hline
\end{tabular}

Carvalho et al. An activity theory-based Computers and 104 (2015). model for serious games Education analysis and conceptual design.

Arnab et al. (2015) Mapping learning and game British Journal of 242 mechanics for serious games Educational Technology analysis.

Mayer et al. (2014) The research and evaluation of British Journal of 112 serious games: Toward a Educational Technology comprehensive methodology.

Erhel y Jamet (2013) Digital game-based learning: Computers and 212 Impact of instructions and Education 
feedback on motivation and learning effectiveness.

Abramovich et al. (2013)
Are badges useful in Educational Technology 169 education? It depends upon Research and the type of badge and Development expertise of learner.
Guillén-Nieto et al. (2012)
Serious games and learning Computers effectiveness: The case of it's Education a deal!

Fuente: elaboración propia.

Respecto al impacto, un 58,8 \% de los documentos analizados cuenta con un índice inferior al esperado, pero hay que destacar que un $41,2 \%$ posee un índice de impacto de citas ponderado superior al esperado. Existe un total de 9 trabajos con un índice superior a 10. Destaca en este campo el trabajo de Arnab et al. (2015) sobre el diseño y evaluación de un serious game considerando, además de los elementos propios del juego, la importancia de la pedagogía, con un índice de 39,70.

Por último, en la figura 7 se muestra la red de citación entre autores, destacando la presencia de los medianos productores que han sido identificados, lo que refuerza su peso en el área de los videojuegos en educación.

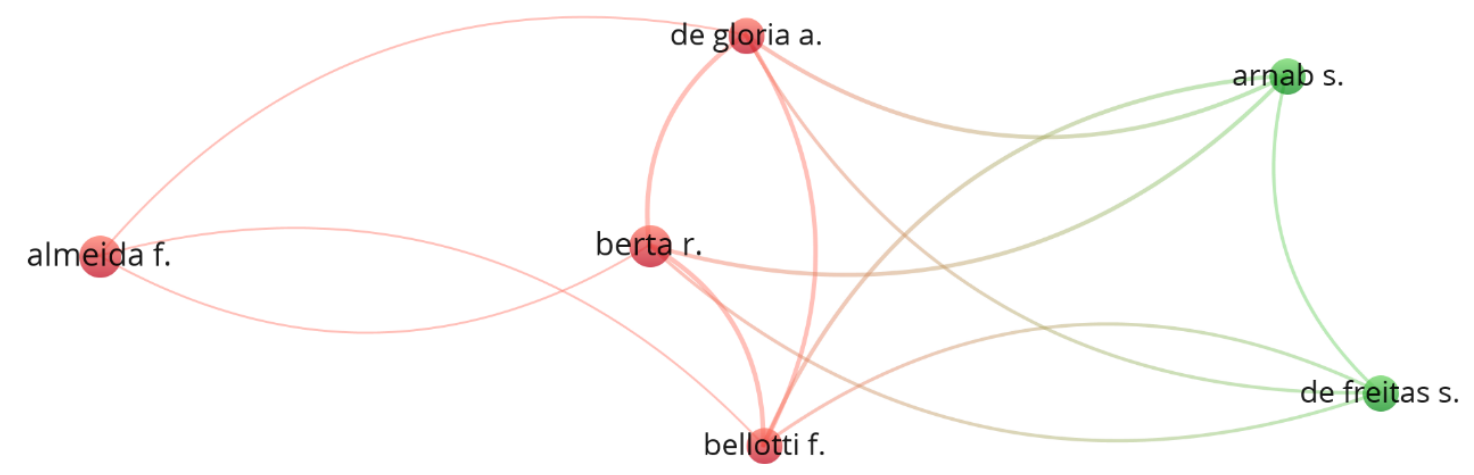

\section{VOSviewer}

Figura 7. Red de citación entre autores

Fuente: vosviewer. 


\section{Análisis de contenido}

El primer nivel de análisis se centra en los términos más utilizados en título, resumen y palabras clave de los documentos seleccionados y en la relación que existe entre ellos. En la figura 8 se ilustra el mapa de redes entre descriptores con base en las coocurrencias, con conteo fraccional (Perianes et al., 2016) y se diferencian 5 clústeres. Por una parte, el primero incluye el concepto de mayor tamaño que es serious games, que se relaciona con game based learning y gamification, identificando términos que se emplean en ocasiones como sinónimos para abordar el estudio de esta temática. El segundo muestra los elementos clave en el proceso educativo, con términos como: learning, curriculum, pedagogy, student o educational technology. El tercer clúster representa aquellas palabras vinculadas con las posibilidades de las tecnologías en el campo educativo como videogames, simulation, recreation o software design. Por otra parte, existe un clúster relacionado directamente con la educación y el aprendizaje, con términos como: computer aided instruction, e-learning, education computing, interactive learning environments, learning system o media in education. Por último, hay un clúster en el que se manifiesta el peso de los estudios centrados en la etapa de educación superior.

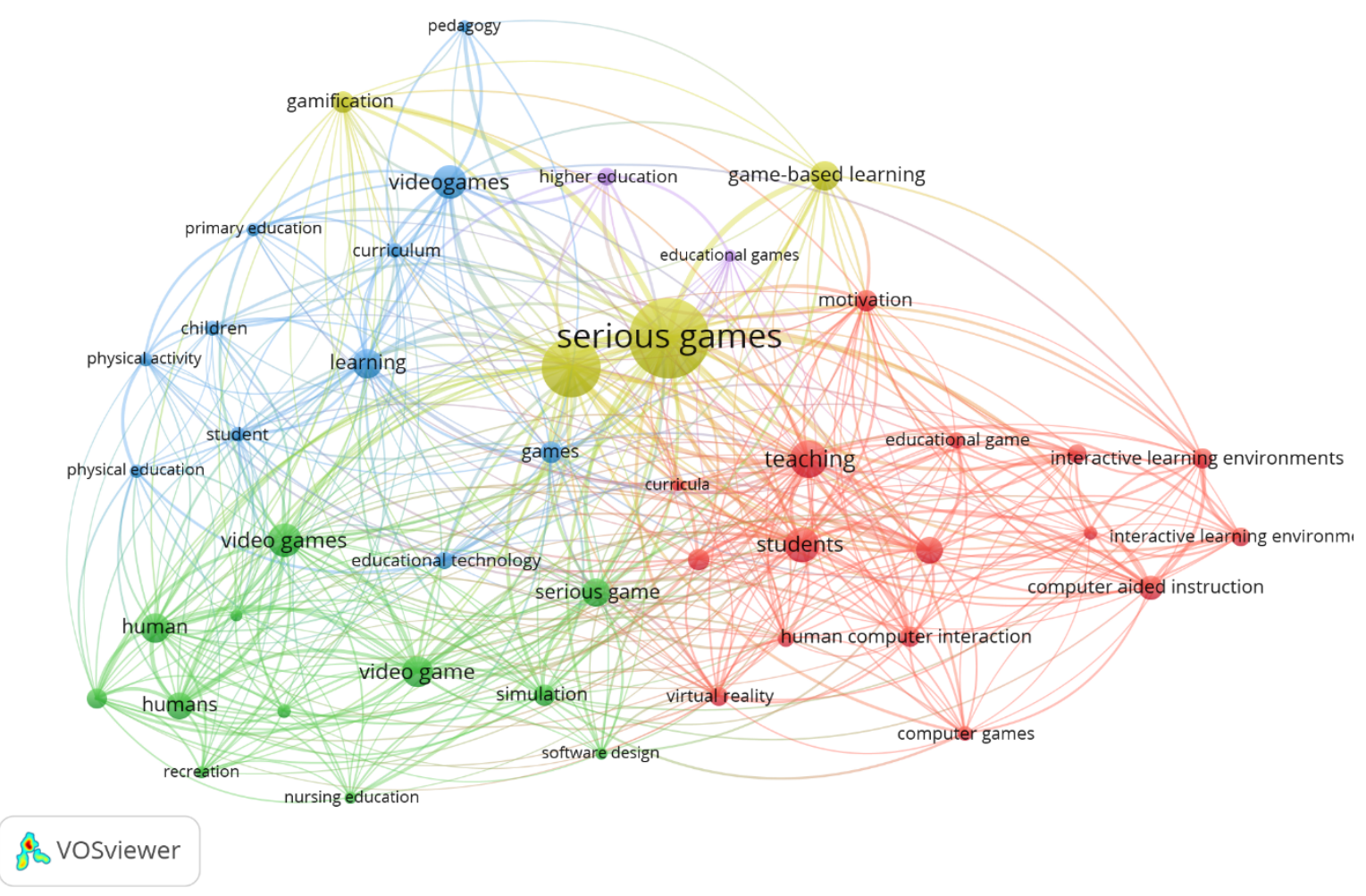

Figura 8. Mapa de coocurrencia de términos

Fuente: vosviewer. 
El segundo nivel de análisis realizado ha profundizado en el contenido de los 62 documentos disponibles en acceso abierto, tomando como categorías para el análisis: la muestra, las etapas educativas, las áreas en las que se emplean los videojuegos y los principales resultados.

En cuanto a los participantes, hay grandes diferencias respecto a la edad (participantes de 5 a 28 años) y al número, yendo de 577 estudiantes (González-Valero et al., 2018) a 6 (Castro et al., 2018), a pesar de tener en común que ambos estudios fueron desarrollados en primaria. También existen diferencias entre géneros en cuanto a las preferencias ante los videojuegos. Según algunos resultados, los chicos, en la etapa de educación secundaria, optan por el ordenador y las chicas por el móvil; además, ellas muestran una responsabilidad mayor tanto en el tiempo de dedicación como en la elección (Ricoy, 2016). Los chicos destinan una gran cantidad de tiempo a los videojuegos de contenido violento, mientras las chicas prefieren los de estrategia y los chicos se sienten más atraídos por las narrativas que incluyen personajes que muestran acciones delictivas y de batalla (Schwarz et al., 2019). Las mujeres se desempeñan mejor en actividades que implican trabajo en equipo y tareas de comunicación (Cela-Ranilla et al., 2014). En general, tanto ellos como ellas prefieren personajes humanos como protagonistas y los personajes no humanos solo como antagonistas. Los hombres son los que más juegan tanto en los días laborables como en el fin de semana y afirman jugar a videojuegos no recomendables para su edad, más que las mujeres (Marín-Díazet et al., 2019).

En cuanto a la etapa educativa, solo 3,22 \% de los documentos se centran en la educación infantil, reconociendo la importancia de los videojuegos para aprender haciendo, en grupo y en un entorno desafiante en el que el alumnado puede experimentar por ensayo/error (Papanastasiou et al., 2017) a edades no tan tempranas. Casi un cuarto de los estudios (22,58 \%) están relacionados con la etapa de Educación Primaria. Entre todos ellos destaca un estudio que relaciona el uso problemático de los videojuegos con la disminución de los niveles de actividad física y el bienestar (González-Valero et al., 2018), o por el contrario, el estudio realizado por Castro et al. (2018), que confirma que los videojuegos son instrumentos capaces de incrementar los niveles de atención, autonomía, autogestión, trabajo en equipo, curiosidad científica y motivación. En la etapa de la educación secundaria destacan las intervenciones para el desarrollo de la educación sexual en el aula (Arnab et al., 2013), así como para fomentar la cultura del éxito educativo, la atención a la diversidad, la inclusión y la convivencia, la educación cívica y política (Saldanha et al., 2018), para el desarrollo de una ciudadanía activa y eficiente (Marín-Díaz et al., 2019), la comprensión de las migraciones de los seres humanos (Su, 2018) y aquellas centradas en los obstáculos y peligros que deben superar las personas refugiadas (Gabriel, 2018), y otras cuestiones consideradas fundamentales para la vida como la inteligencia emocional y la regulación emocional (Cejudo y Latorre, 2015). Respecto a la educación superior, se consideran los videojuegos como estrategia didáctica para facilitar la adaptación a la vida universitaria, la comprensión de nuevos conceptos académicos, buenos hábitos de estudio y de vida saludable y el conocimiento del campus (Moreno y Álvarez, 2020). Otras investigaciones fomentan el uso de videojuegos para el desarrollo de las competencias empresariales, la formación de habilidades de gestión y liderazgo (Almeida y Buzady, 2019), para fomentar el trabajo en equipo y la autogestión (Cela-Ranilla et al., 2014) o para el uso en la clase de informática (Prinsloo y Jordaan, 2014). 
Por su parte, las áreas en las que se emplean los videojuegos educativos son bien diversas, incluyendo su uso para la enseñanza/aprendizaje del inglés (Hansbøl y Meyer, 2011), la bioingeniería o las ciencias de la naturaleza de forma interdisciplinaria (Strawhacker et al., 2018). Asimismo, se plantea entre los estudiantes la creación de videojuegos para fomentar la empatía y los procesos cognitivos (Di Tore, 2014), o para abordar diferentes temas, como la música, la astronomía y el patrimonio cultural, proporcionando entornos de aprendizaje creativos, colaborativos e inclusivos, teniendo en cuenta la interacción auditiva (Rovithis et al., 2019).

Respecto a los resultados obtenidos en general existen trabajos que identifican beneficios del uso de videojuegos para la mejora de la alfabetización digital, detectando las imágenes y noticias falsas, comprendiendo los rastros de la manipulación visual (Katsaounidou et al., 2019). Otros subrayan la importancia de los videojuegos para la alfabetización, las matemáticas, las habilidades cognitivas y motoras, la creatividad, la comunicación y la educación especial (Kokkalia et al., 2017). Destacan aquellos estudios que concluyen que los videojuegos pueden desarrollar la competencia lingüística-comunicativa, teórica y técnica, el desarrollo de la competencia instrumental, en el sentido de gestionar los diversos programas informáticos y aplicaciones que implican la traducción (Esqueda y Fernandes, 2019) y las competencias lectoras (Torres-Toukoumidis et al., 2016). Además, los videojuegos se utilizan para la mejora de las percepciones de riesgo personales y la gestión de la sensación de pánico en condiciones adversas (Bosschaart et al., 2016), y también pueden ser utilizados para desarrollar habilidades de anticipación, el pensamiento sistémico y crítico, la competencia integrada de resolución de problemas, tomar decisiones conscientes y actuar responsablemente según los principios de sostenibilidad (Peña et al., 2020). Del mismo modo, se encuentran artículos referidos a los beneficios de proporcionar una experiencia de narración totalmente inmersiva e interactiva, y el hecho de permitir a los jugadores navegar libremente por el juego tiene un efecto positivo en cuanto al interés (Ferguson et al., 2019), aprovechando la interacción multimodal. Se registran aspectos lúdicos como el entretenimiento, la socialización, la competitividad y el establecimiento de desafíos que influyen en la participación, identificando los elementos y la mecánica del juego (Gonzalo-Iglesia et al., 2018).

En cuanto a la formación inicial de maestros, los videojuegos han demostrado ser útiles para mejorar la competencia lingüística, adquirir conceptos de ciencias naturales y matemáticas, fomentar comportamientos de cuidado, la igualdad de género, la convivencia escolar (Marín-Díaz et al., 2019), y lenguas extranjeras (Alyaz y Genc, 2016). El papel del profesorado como diseñador activo de actividades y recursos para el aula es clave, mezclando videojuegos con otras herramientas y materiales, construyendo una situación de aprendizaje integral (De Sousa y Rasmussen, 2019) y en el desarrollo de una evaluación basada en juegos con una validez de contenido al menos igual a la evaluación tradicional y que parece disminuir los riesgos de la puntuación subjetiva y arbitraria (Hummel et al., 2017). Otros trabajos están vinculados con el ámbito preprofesional, como los que experimentan virtualmente en el espacio de una clínica (Peery y Pasalar, 2018), mejoran la educación en ámbito sanitario (Kron et al., 2010), se centran en la práctica médica (Hannig et al., 2012) o en el ámbito de la Psicología, desarrollando nuevas habilidades (McGregor y Bartle, 2019).

También existen estudios centrados en cuestiones técnicas como el diseño, la producción, el desarrollo de los juegos (Shi et al., 2019; Hanes y Stone, 2019), la evaluación (Borji y 
Khaldi, 2014; Galván-Pérez et al., 2018) o la mejora del lenguaje de programación (Yassine et al., 2017).

\section{Conclusiones}

Respecto al primero de los objetivos centrado en el estudio bibliométrico, destaca el aumento de artículos en los últimos años. El grado de colaboración entre autores de una misma institución o de un mismo país es alto. Se cumple la ley de productividad científica de Lotka y también la ley de Bradford. Hay un predominio claro del inglés como lengua de difusión, a pesar de que España ocupa el primer lugar en el estudio de los videojuegos en el campo de la educación. El índice de impacto de casi la mitad de los artículos es superior al esperado teniendo en cuenta el año de publicación, el tipo de documento y el número de citas recibido.

En cuanto al análisis de contenido, las investigaciones analizadas revelan cómo los videojuegos, al combinar la eficacia del procesamiento informático y el almacenamiento de datos, con altos niveles de atractivo (Bellotti et al., 2010), pueden incrementar la implicación en el proceso de aprendizaje del alumnado gracias a la consideración del contenido, las características técnicas, el estado de ánimo de los usuarios y las características que facilitan el proceso de aprendizaje (Fokides et al., 2019), la fuente de inspiración, el propósito del juego y las competencias a desarrollar (Torres-Toukoumidis et al., 2020).

Como futuras líneas de investigación, es conveniente examinar las percepciones sobre la utilidad y los posibles obstáculos para la aplicación de los videojuegos en el aula (Calabor et al. 2019), la importancia de la formación del profesorado para emplear metodologías cada vez más activas (Galindo-Domínguez, 2019), la necesidad de conocer y elegir adecuadamente entre la gran variedad de productos disponibles, aprovechando los diferentes retos y habilidades cognitivas que cada uno desarrolla (Sedeño, 2010), dado el reducido número de documentos en los que se abordan estas cuestiones.

\section{Agradecimientos}

Esta contribución forma parte los resultados del proyecto emergente titulado "Análisis de las estrategias docentes ante la digitalización de los contenidos del currículum de Educación Infantil y Primaria (GV/2018/074)", financiado por la Conselleria de Educación, Investigación, Cultura y Deporte.

\section{Referencias}

Abramovich, S., Schunn, C. y Higashi, R. M. (2013). Are badges useful in education? It depends upon the type of badge and expertise of learner. Educational Technology Research and Development, 61(2), 217-232. 10.1007/s11423-013-9289-2 
Aleixandre, R. (2010). Bibliometría e indicadores de producción científica. En J. Jiménez, J. M. Argimon, A. Martín y T. Vilardell (eds.), Publicación científica biomédica: cómo escribir y publicar un artículo de investigación (pp. 363-384). Editorial Elsevier.

Almeida, F. y Buzády, Z. (2019). Learning entrepreneurship in higher education throug hflow theory and FLIGBY Game. International Journal of Virtual and Personal Learning Environments, 9(1), 1-15. 10.4018/IJVPLE.2019010101

Altman, D. (1991). Practical statistics for medical research. CRC Press.

Alyaz, Y. y Genc, Z. S. (2016). Digital game-based language learning in foreign language teacher education. Turkish Online Journal of Distance Education, 17(4), 130-146. 10.17718/tojde.44375

Arnab, S., Brown, K., Clarke, S., Dunwell, I., Lim, T., Suttie, N., Louchart, S., Hendrix, M. y De Freitas, S. (2013). The development approach of a pedagogically-driven serious game to support Relationship and Sex Education (RSE) within a classroom setting. Computers \& Education, 69, 15-30. 10.1016/j.compedu.2013.06.013ç

Arnab, S., Lim, T., Carvalho, M. B., Bellotti, F., De Freitas, S., Louchart, S., Suttie, N., Berta, R. y De Gloria, A. (2015). Mapping learning and game mechanics for serious games analysis. British Journal of Educational Technology, 46(2), 391-411. 10.1111/bjet.12113

Bauman, Z. (2003). Modernidad líquida. Fondo de Cultura Económica.

Bellotti, F., Berta, R. y De Gloria, A. (2010). Designing effective serious games: opportunities and challenges for research. International Journal of Emerging Technologies in Learning, 5(2), 22-35. 10.3991/ijet.v5s3.1500

Borji, Y. E. y Khaldi, M. (2014). Comparative study to develop a tool for the quality assessment of serious games intended to be used in education. International Journal of Emerging Technologies in Learning, 9, 50-55. 10.3991/ijet.v9i9.4150

Bosschaart, A., Van der Schee, J. y Kuiper, W. (2016). Designing a flood-risk education program in the Netherlands. The Journal of Environmental Education, 47(4), 271-286. 10.1080/00958964.2015.1130013

Calabor, M. S., Mora, A. y Moya, S. (2019). The future of 'serious games' in accounting education: A Delphi study. Journal of Accounting Education, 46, 43-52. 10.1016/j.jaccedu.2018.12.004

Carvalho, M. B., Bellotti, F., Berta, R., De Gloria, A., Sedano, C. I., Hauge, J. B., Hu, J. y Rauterberg, M. (2015). An activity theory-based model for serious games analysis and conceptual design. Computers and Education, 87, 166-181. 10.1016/j.compedu.2015.03.023 
Castells, M. (1997). La era de la información. Economía, sociedad y cultura. Vol. 1. Alianza Editorial.

Castro, Á. P., Raposo-Rivas, M. y Martínez-Figueira, M. (2018). ¿Mejorar la atención con videojuegos? Un estudio de caso. REOP. Revista Española de Orientación y Psicopedagogía, 29(3), 94-109. 10.5944/reop.vol.29.num.3.2018.23323

Cejudo, J. y Latorre, S. (2015). Effects of the Spock videogame on improving emotional intelligence in adolescents. Electronic Journal of Research in Educational Psychology, 13(2), 319-342. 10.14204/ejrep.36.15060

Cela-Ranilla, J. M., Esteve-Mon, F. M., Esteve-González, V. y Gisbert-Cervera, M. (2014). Developing self-management and teamwork using digital games in 3D simulations. Australasian Journal of Educational Technology, 30(6), 634-651. 10.14742/ajet.754

Cobo, C. y Moravec, J. W. (2011). Aprendizaje invisible. Hacia una nueva ecología de la educación. Publicacions i Edicions de la Universitat de Barcelona.

Chamarro, A., Oberst, U., Cladellas, R., y Fuster, H. (2020). Effect of the frustration of psychological needs on addictive behaviors in mobile videogamers-The mediating role of use expectancies and time spent gaming. International Journal of Environmental Research and Public Health, 17(17), 1-16. 10.3390/ijerph17176429

De Moll, F. (2019). Die alltagsgestaltung von kindern als determinante des schulerfolgs: Wie hängen lesekulturelle und mediale praktiken mit dem erfolg in der grundschule zusammen? Zeitschrift Fur Soziologie Der Erziehung Und Sozialisation, 39(3), 265-280.

De Sousa, F. y Rasmussen, I. (2019). Productive disciplinary engagement and videogames. Nordic Journal of Digital Literacy, 14, 99-116. 10.18261/issn.1891-943x-2019-03-0402

Di Tore, P. A. (2014). Perception of space, empathy and cognitive processes: Design of a video game for the measurement of perspective taking skills. International Journal of Emerging Technologies in Learning, 9, 23-29. 10.3991/ijet.v9i7.3718

Dunbar, N. E., Jensen, M. L., Miller, C. H., Bessarabova, E., Lee, Y., Wilson, S. N., Elizondo, J., Adame, B. J., Valacich, J., Straub, S., Burgoon, J., Lane, B., Piercy, C., Wilson, D., King, S., Vincent, C. y Schuetzler, R. M. (2017). Mitigation of cognitive bias with a serious game: Two experiments testing feedback timing and source. International Journal of Game-Based Learning, 7(4), 86-100. 10.4018/IJGBL.2017100105

Erhel, S. y Jamet, E. (2013). Digital game-based learning: Impact of instructions and feedback on motivation and learning effectiveness. Computers and Education, 67, 156-167. 10.1016/j.compedu.2013.02.019 
Esqueda, M. D. y Fernandes, I. C. (2019). A tradução de jogos para smartphones na sala de aula de ensino de tradução] DELTA Documentacao De Estudos Em Linguistica Teorica e Aplicada, 35(4), 1-33. 10.1590/1678-460×2019350406

Ferguson, C., Van den Broek, E. L. y van Oostendorp, H. (2020). On the role of interaction mode and story structure in virtual reality serious games. Computers \& Education, 143, 1-10. 10.1016/j.compedu.2019.103671

Ferreira, A. (2014). Jeux sérieux et langue de spécialité: Trois exemples de ludification pour l'apprentissage de l'anglais naval. Recherche et Pratiques Pedagogiques en Langues de Specialite - Cahiers De I'APLIUT, 33(1), 66-90. 10.4000/apliut.4176

Finco, M. D. y Fraga, A. B. (2012). Rompendo fronteiras na Educação Física através dos videogames com interação corporal. Motriz. Revista De Educacao Fisica, 18(3), 533541. 10.1590/S1980-65742012000300014

Finco, M. D., Reategui, E. B. y Zaro, M. A. (2015). Laboratório de exergames: Um espaço complementar para as aulas de educação física. Movimento, 21(3), 687-699.

Fokides, E., Atsikpasi, P., Kaimara, P. y Deliyannis, I. (2019). Factors influencing the subjective learning effectiveness of serious games. Journal of Information Technology Education, 18, 437-466. 10.28945/4441

Gabriel, S. (2018). How to analyze the potential of digital games for human rights education. Revista Lusófona de Educação, 41, 29-43. 10.24140/issn.1645-7250.rle41.02

Galindo, H. (2019). Los videojuegos en el desarrollo multidisciplinar del currículo de educación primaria: el caso Minecraft. Pixel-Bit, 55, 57-73. 10.12795/pixelbit.2019.i55.04

Galván-Pérez, L., Ouariachi, T., Pozo-Llorente, M. y Gutiérrez-Pérez, J. (2018). Outstanding videogames on water: A quality assessment review based on evidence of narrative, gameplay and educational criteria. Water, 10(10), 1-30. 10.3390/w10101404

García, I., Gallardo-López, J. A. y López-Noguero, F. (2020). La inteligencia emocional y la educación emocional en la escuela: un estado de la cuestión a través del análisis bibliométrico de la producción científica en Scopus (2015-2019). En J. A. Marín, G. Gómez, M. Ramos y M. N. Campos (coords.), Inclusión, tecnología y sociedad (pp. 220231). Dyckinson S. L.

González-Valero, G., Ubago-Jiménez, J. L., Zurita-Ortega, F., Chacón-Cuberos, R., CastroSánchez, M. y Puertas-Molero, P. (2018). Eating habits and lifestyles in schoolchildren from Granada (Spain). A pilot study. Education Sciences, 8(4), 1-10. 10.3390/educsci8040216.

Gonzalo-Iglesia, J. L., Lozano-Monterrubio, N. y Prades-Tena, J. (2018). Noneducational board games in university education: Perceptions of students experiencing Game-Based 
Learning methodologies. Revista Lusófona de Educação, 41(41), 45-62. 10.24140/issn.1645-7250.rle41.03

Guillén-Nieto, V. y Aleson-Carbonell, M. (2012). Serious games and learning effectiveness: The case of it's a deal! Computers and Education, 58(1), 435-448. 10.1016/j.compedu.2011.07.015

Hanes, L. y Stone, R. (2019). A model of heritage content to support the design and analysis of video games for history education. Journal of Computers in Education, 6(4), 587612. $10.1007 / \mathrm{s} 40692-018-0120-2$

Hannig, A., Kuth, N., Özman, M., Jonas, S. y Spreckelsen, C. (2012). eMedOffice: A webbased collaborative serious game for teaching optimal design of a medical practice. BMC Medical Education, 12(1), 1-15. 10.1186/1472-6920-12-104

Hansbøl, M. y Meyer, B. (2011). Shifting ontologies of a serious game and its relationships with English education for beginners. E-learning and Digital Media, 8(3), 228-246. 10.2304/elea.2011.8.3.228

Hummel, H. G., Joosten-ten Brinke, D., Nadolski, R. J. y Baartman, L. K. (2017). Content validity of game-based assessment: Case study of a serious game for ICT managers in training. Technology, Pedagogy and Education, 26(2), 225-240. 10.1080/1475939X.2016.1192060

Katsaounidou, A., Vrysis, L., Kotsakis, R., Dimoulas, C. y Veglis, A. (2019). MAthE the game: A serious game for education and training in news verification. Education Sciences, 9(2), 1-15. 10.3390/educsci9020155.

Khaled, R., y Vasalou, A. (2014). Bridging serious games and participatory design. International Journal of Child-Computer Interaction, 2(2), 93-100. 10.1016/j.ijcci.2014.03.001

King, J. (1987). A review of bibliometric and other science indicators and their role in research evaluation. Journal of Information Science, 13(5), 261-276. $10.1177 / 016555158701300501$

Kirby, A. (2009). Digimodernism: How new technologies dismantle the postmodern and reconfigure our culture. Bloomsbury Publishing USA.

Kokkalia, G., Drigas, A., Economou, A., Roussos, P. y Choli, S. (2017). The use of serious games in preschool education. iJET, 12(11), 15-27. 10.3991/ijet.v12.i11.6991

Kron, F. W., Gjerde, C. L., Sen, A. y Fetters, M. D. (2010). Medical student attitudes toward video games and related new media technologies in medical education. BMC medical Education, 10(1), 1-11. 10.1186/1472-6920-10-50 
Lanzotti, A., Vanacore, A., Tarallo, A., Nathan-Roberts, D., Coccorese, D., Minopoli, V., Carbone, F., d'Angelo, R., Grasso, C., Di Gironimo, G. y Papa, S. (2020). Interactive tools for safety 4.0: Virtual ergonomics and serious games in real working contexts. Ergonomics, 63(3), 324-333. 10.1080/00140139.2019.1683603

López, I., Avello, R., Avello, Baute, L. M., y Vidal, M. (2018). Videogames in higher education. Revista Cubana de Educación Médica Superior, 32(1), 264-276.

Marín-Díaz, V., Morales-Díaz, M. y Reche-Urbano, E. (2019). Educational possibilities of video games in the primary education stage according to teachers in training. A case study. Journal of New Approaches in Educational Research, 8(1), 42-49. 10.7821/naer.2019.1.330

Marín-Díaz, V., Sampedro-Requena, B. E. y Mac Fadden, I. (2019). Perceived utility of video games in the learning process in secondary education-Case studies. Sustainability, 11(23), 1-13. 10.3390/su11236744

Martínez-Heredia, N. y Moreno, M. B. (2020). Impacto de la producción científica acerca de la educación para muerte: revisión bibliométrica en Scopus y Web of Science. RIE, 82(2), 65-79. 10.35362/rie8223553

Mayer, I., Bekebrede, G., Harteveld, C., Warmelink, H., Zhou, Q., Van Ruijven, T. y Wenzler, I. (2014). The research and evaluation of serious games: Toward a comprehensive methodology. British Journal of Educational Technology, 45(3), 502-527. 10.1111/bjet. 12067

McGregor, G. y Bartle, E. (2019). The creation and trial of a serious game to support teaching and learning of professional psychology competencies in postgraduate programs. Australasian Journal of Educational Technology, 35(5), 15-28. 10.14742/ajet.4237

Moreno, A. J. (2019). Estudio bibliométrico de la producción científica sobre la inspección educativa. REICE, 17(3), 23-40. 10.15366/reice2019.17.3.002

Moreno, J. y Álvarez, J. A. (2020). Videojuego móvil como estrategia didáctica para facilitar la adaptación a la vida universitaria. Formación Universitaria, 13(1), 55-62. 10.4067/S0718-50062020000100055

Papanastasiou, G., Drigas, A. y Skianis, C. (2017). Serious games in preschool and primary education: benefits and impacts on curriculum course syllabus. International Journal of Emerging Technologies in Learning, 12(01), 44-56. 10.3991/ijet.v12i01.6065

Peery, J. G. y Pasalar, C. (2018). Designing the learning experiences in serious games: the overt and the subtle-the virtual clinic learning environment. Informatics. Multidisciplinary Digital Publishing Institute, 5(3), 1-14. 10.3390/informatics5030030 
Peña Miguel, N., Corral Lage, J. y Mata Galindez, A. (2020). Assessment of the development of professional skills in university students: Sustainability and serious games. Sustainability, 12(3), 1-18. 10.3390/su12031014

Perianes-Rodriguez, A., Waltman, L. y Van Eck, N. J. (2016). Constructing bibliometric networks: A comparison between full and fractional counting. Journal of Informetrics, 10(4), 1178-1195.

Prinsloo, J. W. y Jordaan, D. B. (2014). Selecting serious games for the computer science class. Mediterranean Journal of Social Sciences, 5(21), 391-391. 10.5901/mjss.2014.v5n21p391

Ricoy, C. (2016). Preferencias, dedicación y problemáticas generadas por los videojuegos: Una perspectiva de género. Revista Complutense de Educación, 27(3), 1291-1308. doi.org/10.5209/rev_RCED.2016.v27.n3.48445

Romaní, C. C. y Moravec, J. W. (2011). Aprendizaje invisible: hacia una nueva ecología de la educación (Vol. 3). Edicions Universitat Barcelona.

Rovithis, E., Floros, A., Moustakas, N., Vogklis, K. y Kotsira, L. (2019). Bridging audio and augmented reality towards a new generation of serious audio-only games. Electronic Journal of e-Learning, 17(2), 144-156. 10.34190/JEL.17.2.07

Saldanha, L., Pinto, M. y Ferreira, P. D. (2018). Unmanned: Dimension politique et civique du jeu vidéo. Revista Lusofona De Educacao, 40(40), 181-197. 10.24140/ISSN.16457250.RLE40.12

San Martín, A. (1995). La escuela de las tecnologías. Universitat de València.

Saravanan, M. y Balasaravanan, T. (2018). Videogame playing and aggression behaviour: A correlation study among school students. Media Watch, 9(2), 209-218. 10.15655/mw/2018/v9i2/49383

Schwarz, A., Mertens, L., Simons, M., Spook, J. E., Thompson, D., Cardon, G., De Bourdeaudhuij, I., Chastin, S. y DeSmet, A. (2019). Which game narratives do adolescents of different gameplay and sociodemographic backgrounds prefer? A mixedmethods analysis. Games for Health Journal, 8(3), 195-204. 10.1089/g4h.2017.0178

Sedeño, A. (2010). Videojuegos como dispositivos culturales: las competencias espaciales en educación. Comunicar, 17(34), 183-189. 10.3916/C34-2010-03-018

Shi, W., Kaneko, K., Ma, C. y Okada, Y. (2019). A framework for automatically generating quiz-type serious games based on linked data. International Journal of Information and Education Technology, 9(4), 250-256. 10.18178/ijiet.2019.9.4.1208

Sipiyaruk, K., Gallagher, J. E., Hatzipanagos, S. y Reynolds, P. A. (2017). Acquiring critical thinking and decision-making skills: An evaluation of a serious game used by 
undergraduate dental students in dental public health. Technology, Knowledge and Learning, 22(2), 209-218. 10.1007/s10758-016-9296-6

Smallenbroek, B., De Vries, R., y Lindhout, A. (2015). 'Op eigen kracht': innovatieve serious game als geaccrediteerde nascholing over zelfredzaamheid voor huisartsen ook geschikt voor bedrijfsartsen. TBV-Tijdschrift voor Bedrijfs-en Verzekeringsgeneeskunde, 23(2), 67-70. 10.1007/s12498-015-0030-4

Strawhacker, A., Bers, M., Verish, C., Sullivan, A. y Shaer, O. (2018). Enhancing children's interest and knowledge in bioengineering through an interactive videogame. Journal of Information Technology Education: Innovations in Practice, 17(1), 55-81. $10.28945 / 3976$

Su, C. H. (2018). Exploring sustainability environment educational design and learning effect evaluation through migration theory: An example of environment educational serious games. Sustainability, 10(10), 1-26. 10.3390/su10103363

Tomás-Górriz, V. y Tomás-Casterá, V. (2018). La bibliometría en la evaluación de la actividad científica. Hospital a Domicilio, 2(4), 145-163. 10.22585/hospdomic.v2i4.51

Torres-Toukoumidis, A., Romero-Rodriguez, L., Amor, M. y Bjork, S. (2016). Development of reading skills through video games: state of the art. OCNOS, 15(2), 37-49. 10.18239/ocnos_2016.15.2.1124

Torres-Toukoumidis, A., Salgado, J. P., Peñalva, S. y Carrera, P. (2020). Global Game Jam in Latin-America, a collaborative videogame learning experience. Social Sciences, 9(3), 28, 1-11. 10.3390/socsci9030028

Van Eck, N. J. y Waltman, L. (2011). Text mining and visualization using VOSviewer. arXiv preprint arXiv: 1109.2058

Yassine, A., Chenouni, D., Berrada, M. y Tahiri, A. (2017). A serious game for learning C programming language concepts using solo taxonomy. IJET, 12(03), 110-127. 10.3991/ijet.v12i03.6476

Zulueta, M. A. y Bordons, M. (1999). A global approach to the study of teams in multidisciplinary research areas through bibliometric indicators. Research Evaluation, $8(2), 111-118.10 .3152 / 147154499781777612$ 